\title{
A Study of Rural Self-organization and Cultural Reconstruction from the Perspective of New Rural Cultural Construction
}

\author{
Juan Zhou \\ The School of Law and Politics \& Administration \\ Guangdong Ocean University \\ Zhanjiang, China 524088
}

\author{
Facheng Gao* \\ The School of Law and Politics \& Administration \\ Guangdong Ocean University \\ Zhanjiang, China 524088 \\ *Corresponding author
}

\begin{abstract}
During the state building the socialist new rural culture, the rural self-organization by the body of councils, associations, and so on, became active on the stage of new rural cultural construction to deal with folk beliefs and cultural activities of the collective events, and to promote the villagers' autonomy which caused the wide attention of researchers. Villagers of self-organization to strengthen the folk beliefs of enlightenment, also strengthened the group self-discipline and norms of behavior, is beneficial to maintain the good social and economic order, then the construction of new socialist countryside culture provides a huge organization guarantee and intellectual support.
\end{abstract}

Keywords-new rural cultural construction; rural selforganization; cultural reconstruction; social integration

\section{INTRODUCTION}

Focusing on the reconstruction of rural culture ultimately is to focus on the cultural matters in construction of socialism new countryside. With the accelerating process of modernization and urbanization, it has great impacts on rural traditional culture without a doubt. In addition, custom-based rural traditional culture was severely destroyed in "demolish \& establish" ages. While, in the era when culture becomes the core content of soft power of a country and is considered as a standard to measure the comprehensive strength of a country, how to reconstruct rural culture becomes the current hot issue we should focus on. Through investigation on villages in west area of Guangdong, we find that some self-organizations existing in rural area have utmost link with the recovery and reconstruction of traditional culture. Therefore, by concerning the development status of rural self-organization, it will make them become "close friends" of villagers themselves, even "bridge" which connects the villagers committee; moreover, it will combine the cultural matters villagers care with the community construction to contribute material power of

[Fund project] Phased achievements of 2014 project "Rural Selforganization and Cultural Reconstruction from the perspective of New Rural Cultural Construction" (No.: GDOU2014050235) supported by "innovative school project" of Guangdong Ocean University and "Study on Rural Selforganization from the perspective of Yearly Worship in West Guangdong" (No.: C14541) the key research project of 2014 humanistic and social sciences of Guangdong Ocean University. socialism new countryside business in current urbanization construction, which will achieve many objectives at one stroke.

\section{NATIONAL RURAL SELF-ORGANIZATION GERMINATED ON RURAL SOCIAL BASIS: DEFINITION AND CONNOTATION}

In recent years, many sociologists have started paying high attention on self-organization theory. However, the current research on self-organization is still in preliminary exploration stage and does not form perfect theoretic system capable of guiding practice. Most scholars mainly study rural selforganization on the effects of rural self-organization, economic cooperation organization and villager rights protection organization on participating in society treatment, mutual economic assistance and service guarantee functions, less involved in researching on the existing active rural cultural construction organization. The definition of rural selforganization is one of the key academic issues. It is proposed by some scholar that, the existence of self-organization in rural area is born of the traditional blood relationship and geographical relationship of rural society, driven by certain mutual benefit, the members participated have similar perspectives in terms of affairs at village level or villager relationship; moreover, such organization is spontaneously organized and it has four characteristics: firstly, it is neither permitted nor prohibited legally which is the precondition of establishing informal organization; secondly, among the members, there is some invisible affection tie organizing them together, such as trust, demand, etc. which is the foundation and ultimate for establishment of rural informal organization; thirdly, spontaneity of organization establishment, which is the base point differing from formal organization; fourthly, the organization exists in rural areas, which the external environment for the establishment, development and function of the organization. [1] The analysis above constructs the establishment and development mechanism of rural selforganization from members and their geographical nature; however, it does not focus on the process of establishment and development of rural self-organization and reason of its existence. As a result, Qiu Guiming initially explores the definition of rural self-organization (so called "peasant selforganization") in the article of Discussion on Peasant Self- 
Organization - One Practice in Theoretical Dispute and New Rural Construction [2], and it points that, voluntary is the basic principle of the organization and the organization disposes affairs mainly based on public communication; in the meanwhile, it can form articles to dispose corresponding affairs by means of independent decision-making; hence, such rural self-organization characterizes "voluntary, autonomy and public welfare". The research defines its definition and the characteristics of the rural self-organization and its members; however, the definition is over generalization hard to differ to village self-government organization. Hence, concerning the way to learn "self-organization", Li Yongcai and Yuan Yonghong [3] consider, from the perspectives of space, time or function of the group in structure acquirement process, selforganization as a system intervened by specific external environment, and prescribe a limit to "specific" - refer to structure or function acting on the system by the external environment in an unspecific way instead of which imposed to the system by the external environment. In this analysis, it finally points the operation mode of the self-organization from the member nature to organization characteristics, but the specific image of participant "peasant" is still hard to see. Therefore, by sorting the process of organizing peasants in rural self-organization in his discussion, Wu Jie [4] thinks that, in the socialism new countryside construction process, on one hand, peasants formally participate in rural constructions led by the village self-governance committee established by villager non-governance system, so that various passivity factors exist; on the other hand, because of voluntary choice, it strengthens their abilities and make them become the main body of cultural construction by informal means, e.g. cooperation organization, culture \& folk custom organization and socialization service organization, etc. In conclusion, the rural self-organization takes peasants as carriers, cultural activities as objectives and constructs a public-welfare system through voluntary and spontaneous collective actions, and starts its course of participating in the new countryside cultural construction.

$\mathrm{H} \cdot$ Haken, German theoretical physicist, founder of synergetics theory, defines "self-organization" as: in case of no specific intervention in the process of the system obtaining the space, time or functional structures, we can consider such system is self-organization. "Specific" herein refers to structure or function acting on the system by the external environment in an unspecific way instead of which imposed to the system by the external environment [5]. In Haken's opinion, from the view of the driving force of organization establishment, some organizations are formed and maintained depending on external power, i.e. other-organization; while, the other organizations run in order because it can form harmonious rules internally and its structures are able to do their own duty and properly coordinate, "the process is generated spontaneously, not led or controlled by any medium or the internal or external subsystem of the system" [6], i.e. selforganization; however, the stronger of the organization's function, it will have further stronger desire to generate new functions. Hence, the writer thinks that, the rural selforganization of our country is a group established by peasants according to local rules and regulations valid for the whole village for purpose of treating non-political events, especially involved in culture and concerning villagers' collective benefit, which takes the organization forms of council, association and so on as carriers, communicates and organizes villages to conduct cultural activities.

China is an ancient country with history of 5000 years, during the 5000 years of development, at the same time of continuously creating cultures, it "loses" some cultures as well. In western Guangdong area, especially in rural community, they carry on the basic contents and value of folk religion as before in forms of religious self-organization. Mr. Zheng Hangsheng proposed before in his research on "modern and tradition" [7] that, up to present, various traditional cultures are not "original cultures" any more, instead, they are "invented", "reformed" or "newly formed" traditional culture. So called cultural reconstruction, it refers to "reforming" the existing traditional culture, giving modern meaning to the traditional culture and abandoning the improper things, so as to turn it to be a culture in same form but with different meanings which can adapt to the development of socialist society as well. In rural areas, the continuation and reconstruction of traditional culture and folk custom owe to these rural self-organizations. The essence of the self-organization is evolved from the Presbyterianism of feudal society, which becomes the key carrier of reconstruction of rural culture. In the meanwhile, these organizations are showing their ability of generating new functions, especially in parts which cannot be stipulated or governed by the self-government system in rural political construction, benefit irresistible for rural self-government committee exists, which becomes the "effective supplement" of the "nerve endings" of rural self-government committee [8]; moreover, such organization ability generates will of guaranteeing the equalization of the community as well, once breakage of such equalization in treatment of affairs, members of the organization will spontaneously take rationality as orientation and make efforts to re-equalization of production.

\section{THE DisPUTATION OF RURAL SELF-ORGANIZATION: DESTROY SOCIAL ORDER OR INTEGRATE SOCIAL STRENGTH}

So why is there a phenomenon of rural self-organization? Cai Weihong and Zhong Xiaolin [9] point out that the internal motivation of the birth of rural folk organization relies on the diversified interest demands of villagers and the uncovering areas of government's function or inefficient rural public areas. Rural non-governmental organization refers to the autonomous rural social organization formed by villagers with meeting the demands of material and culture. The author also states that in the process of the transition from traditional rural society to modern society, the traditional community culture disappeared and the common historical memory broke down due to the dual effects of social change and market economy. Tian Jinna [10] thinks that the generating mechanism of rural self-organization is composed of conditional mechanism, dynamic mechanism, and evolutional mechanism. Conditional mechanism refers to external information and material incentive and the growth of villagers' self-spiritual strength, which is the result of those contents being input into rural areas. Dynamic mechanism is influenced by the drive of economic factors. Evolutional mechanism refers to that there are two approaches in the process of constructing rural self-organization: one way is derived from the fact that farmers are organized, or the 
coexistence of farmers being organized and self-organized, and the two eventually reach self-organization in the competition. And the other way is the evolution from being organized to self-organizing. This understanding is based on the fact that self-organization establishes the basis on the resistance of farmer's "be" event. However, Tong Yuquan and Deng Guangyu [11] further analyze rural self-organization from the perspective of legitimacy and they divide rural organization into interior system and exterior system. According to national policy, the establishment of the villagers' representative meeting, the family planning association, the rural cooperative economic organization, Youth League branch and group of villagers are listed into interior system. Although they have little legal registration, they are recognized by the government. While the establishment of farmer's rights organizations and the clan organizations with local characteristics have no legal status and the recognition from relevant government department. Compared with the two systems, the exterior organization gets more acknowledgements form villagers. Consequently, scholars further point out that "the reason why rural non-governmental organizations can be involved in the construction of new rural areas and become the main force is because there is a certain degree of failure in the government and market as a theme of the first class governance. As a kind of adhesive, the rural folk organizations can organize the rural areas of atomization, and the rural folk organizations can set up social capital and construct the horizontal network of citizens." [12] Which shows that rural self-organization seems to have the ability to destroy the order of system.

So, how does the specific rural self-organization operate? $\mathrm{Mr}$.Yu Jianrong [13] takes peasant association as a kind of rural self-organization into consideration, through the content and method of its operation, and states that rural selforganization probably is not the resistance strength to destroy some systems and orders. However, with the ability of selfexisting, and peasant association becomes the power of social integration. The three rural issues of China is actually a political issue. There is a political crisis existing in China's countryside, and the reconstruction of peasant organization such as rural self-organization can be benefit to villagers to express their interest demands. To some extent, it helps to defuse the crisis and maintain social stability and promote economic development. Ruan Yunxing and some scholars [14] describe an endogenous organization of Liu village in the east of Zhejiang province--Liu Laohui endogenous tissue (society for the elderly). They describe the condition of its internal operation and the strength in this village, and indicate that this kind of endogenous organization will benefit the development of rural civil society and will become an important strength in new rural areas. We should take public domain as a basis in order to build a modern country, and it must be rural public domain in countryside. Therefore, this kind of endogenous organization can offer human resources and material resources to carry out the modernization construction, which is the occurrence and growth of rural self-organization. Although in the specific case, we can see the effect of this kind of organization on modern rural construction by discussing the operation mode of rural self-organization, but we also should pay attention to the problems raised by some opposed scholars. As early as more than ten years ago, Yang Ping [15] in his study stated that Chinese rural self-organization has shown its strong vitality, in which family organization with traditional influence is the most important style. Family organization and state power at the grass-roots level has more broad space for cooperation, and this is mainly reflected in the grassroots democratic elections, which will choose a person with virtue and high prestige in the family, although it is diametrically opposed by the modern mainstream, this is a double-edged sword and has its two sides. Qiao Xinsheng and other scholars [16] further believe that this kind of self-organization like peasant association with family background probably become a second committees, which is not conducive to the stability of rural communities.

In academic circles, there are different opinions about the ability of rural self-organization members. Some scholars think that Chinese peasants have the characteristics of typical atomization, low cooperation ability and not suitable for selforganization. However, some opposed scholars believe that as the farmers of self-organization members, whether it is knowledge and skills or social communication ability, are different from the owner-peasants in natural economy condition. They increasingly accept the impact of socialization and become a member of society, however, with the character of natural profit-orientation, they more adapt to the systematization of interest-orientation, and so rural selforganization is based on the reasonable development without interference. In fact, whether you support or against it, selforganization in rural areas of China has developed, and it can form a good complement to the village committee in the specific operation to promote the work of the village committee.

In the west of Guangdong province, religious ceremonies are organized by rural traditional beliefs, including God ritual ceremony, exorcising dance and the show of lion dance, which are all organized by the prestige person, and it was implemented by the elders rule in the past raised by Fei Xiaotong. However, modern society has removed the elders rule with the double meaning of politics and morality, and replaced it by the "council" to handle modern economic relations. Dongling village in Zhanjiang city puts Linggang Temple as a center of religious ceremony--exorcising dance. In order to ensure that the annual Lantern Festival performances of exorcising dance can go smoothly, the villagers themselves found the "council". According to the introduction by general leader of the council, Mr. Lin, exorcising dance is passed on by a generation of old people, and is spontaneously organized by villagers in hundreds of years. Since the last century in 80 s, the word of "council" was put forward by people, it has been used until now. The council has more than 30 people, including a general manager, a financial manager and the rest of the auxiliary staff. The internal members with high prestige are respected by villagers. It is different from the democratic election of the village committee election, and the election of the council has a sense of religion. There is a Linggang Temple in Dongling village, in which a "God Male" statue is worshiped by villagers, and they all believe that the general manager of the council is selected by "God Male". The specific step is like this: firstly, "God Male" will choose a wonder child; secondly, there is a phenomenon that "God" will go into the 
body of this wonder child, then the wonder child will say the name of a villager, and this person will be selected as the general manager of the council. The current wonder child is affirmed through a special way: Four years ago, the 18th day of the second month of the Chinese lunar calendar, a child could not sleep well in his room about half a month and then he went out to Linggang Temple, but surprisingly he slept well for 4 hours in this temple, and so the villagers believed he was the new wonder child. The general manager has no fixed term, and if the "God Male" doesn't appoint a new person, and this general manager will have to remain in his position. The rest people are elected by the villagers, and they generally have a strong ability to work and a solid foundation of the masses. In the opinion of Mr. Lin, there is a different way of leadership in the council and the village committee, but the actual work tasks of the two is to coordinate and promote each other. The council is entirely based on public welfare, and the staffs have no paid and they are entirely voluntary to serve for the villagers. The members of the council are joined by a voluntary basis, so the organization has a strong sense of consciousness. This will ensure that the village committee collaborates with the council to finish the task to promote the harmonious development of the village, such as the maintenance activities of roads and other infrastructure of the village, and villagers will actively cooperate with the committee's work under the council's initiative.

\section{RURAL SELF-ORGANIZATION GIVES GREAT CONTRIBUTIONS TO THE RECOVERY OF TRADITIONAL Culture and the Promotion of NeW RuRal Cultural CONSTRUCTION}

Through analyzing and sorting the studies of scholars, we can learn about that self-organization has played an important role in the process of new rural cultural construction and the important effects are listed as follows: (1)To solve the problem of the lack of funds for rural cultural construction; (2)To solve the problem of the lack of talents in rural cultural construction; (3)In favor of making up the lack of local government rural cultural management mechanism and to construct a longlasting new rural cultural construction mechanism; (4)The cultural products provided by self-organization have more pertinence and can meet the cultural demands of farmers. They can squeeze and deprive the living space of backward and decadent culture, which can be beneficial to the healthy development of new rural cultural construction. (5) The rural clan organization gives a great sense of belonging to the villagers and enhances the cohesion of villagers in the family, and it offers a harmonious environment to cultural construction. Rural clan organization playing such an important role may derive from the popular religion of the traditional rural society. Although villagers who live in the rural areas become more and more modernized, there still are ecological environment for the development of popular religion in rural society. The reason why the construction of new socialist countryside culture puts the first step in the construction of traditional culture is that the rural cultural strength exists in the popular religion." It has given great contributions to ecological stability, cohesion and unity, harmony and orderly, and the normal operation of the society" [17]. This is the spontaneous collective behavior of farmers for this faith being inherited. If this kind of cultural construction cannot be undertaken by rural self-organization, no other organizations can be trusted by the farmers and they cannot bring benefits to farmers and rebuild the culture in the same time.

Some scholars [18] point out that in the process of urbanization of our country, there is a fracture and imbalance and social identity crisis in the development of rural culture, the urgent things that we need to build the rural memory and rural cultural organization to explore the social identity of the rural cultural construction. In order to deal with the rural community from the "acquaintance society" into a "stranger society", we should develop the folk cultural organization, promote the development of rural culture, and unite the villagers. So what are the restrictions on the development of rural self - organization? Liu Wei [19] in his essay has pointed out that the degree of self-organization of farmers is low, and the reasons for the low degree of self-organization are explained from several aspects. He also pointed out that the development of Chinese rural areas in the future must take the road of self-organization of farmers, and the villagers can better protect and realize their own interests just because of self-organization. When he does the research of rights keeping organization of farmers, Yu Jianrong [20] points out that selforganizations are mostly "informal organization" and have not got the qualification to "formal organization". Because of the lack of systematicness and ascendance, there is no relationship between rights and obligations in members. As a whole, the current academic research suggests that the rural selforganization joining in the new rural culture construction is generally facing some plights as follows: (1) The lack of rural cultural construction funds and slow construction of cultural infrastructure; (2)The shortage of rural cultural professionals; (3)The feudal and decadent ideology and culture still exist in the rural areas. (4)The identity of self-organization is awkward and management mechanism is not sound.

However, the rural self-organization plays an important role in the vital organization and safeguard function in the reconstruction of the local social culture, which is an important factor for the collective cultural activities to flourish in the rural areas. At present, rural culture is at the edge of fracture and decline, and an important factor is the lack of spontaneous cultural organization in rural areas, and the key of reconstruction of rural culture is to stick to culture management by them. In the process of studying Jiuxi culture, Zhang Dinggui [21] points out that the cultural tradition of Jiuxi village nourish a complete self-organization mechanism, and this unique cultural tradition and self-organization have constructed each other. However, the rural elite who are born from the organization are the joint point of its construction. $\mathrm{He}$ believes that the so-called rural self-organization mechanism is just the capability of the villagers to integrate the selforganization and self-management in the inheritance of social cultural activity. From the perspective of solving the problem of small farmers, Cao Jinqing [22] in his work at the edge of the China at the Yellow River states that the less-development of self-organized capability of farmers is the deep-seated reason that our countryside is difficult to step out of tradition and step into modernization. Based on the experience of Yu's study of "rural construction" in Taiwan, it demonstrates that 
villagers can achieve the rural development plan only by farmers organizing themselves. Following this thought, scholars put emphasis on how to organize and participate in and construct the rural culture by farmers' themselves in their subsequent research and this requires the development of rural self-organized strength. Wang Yuling [23] in her research points out that the traditional rural folk culture is on the decline and it is a trend to reconstruct the rural culture. The reconstruction of rural culture puts emphasis on the transformation of farmer's core cultural values. It is an urgent thing to transform and recombine the modern culture and traditional culture, urban culture and rural culture, oriental culture and western culture, which have exerted some important effects on rural areas and the most important thing is we should seek the harmonious point. Furthermore, the methods of reconstruction are to inherit, sublate and innovate and we also need to build a cultural organization which is based on farmers. The constructive factor of rural traditional culture is the folk religion which reflects the interests and needs of rural community's common cultural life; however, the objective factor of rural self-organization is to reconstruct traditional culture which is based on the rural genetic and geographical relationship network. In the history of China, the cultural presentation was interrupted by politics and it is bound to be renewed because of politics. After the reform and opening to the outside world, the rural cultural renaissance movement is built by the way of rural self-organization, which combines tradition with modernity, and balance politics and economy, so the supply of folk religion becomes a bond which combines self-organization with reconstruction of culture. Meanwhile, the ecological, structural and functional features of the rural public community depicted by the rural selforganization and cultural reconstruction are the result of Modernity, and we should recognize the significant influence, status and function of rural self-organization in this community Except for a few negative effects, rural self-organization can meet the demands of modern development of rural traditional culture. Rural self-organization also exerts some positive impacts on ecological stability, cohesion and unity, harmony and order, the normal operation of community life in the new rural cultural construction. This is the primary reason for the rural cultural reconstruction from tradition to modern development, and is also an important guarantee for the continuation of traditional culture.

The devotional organization of Dongling village temple initially exists in the way of elders rule, and they manage the activity, exorcising dance and yearly customary practices of village temple. After the founding of People's Republic of China, Dongling village has also experienced a process of abandoning the tradition and the elder rule naturally is no longer in existence. Until the reform and opening-up, with the economic condition of villagers becoming better, our country begin to support the new rural cultural construction, and the folk religion of the removed dross again go on the stage of rural life as the main force of cultural reconstruction. Dongling village also rebuilt the Ling Gang temple, and it is regarded as a center to carry out the religious activities to unite the strength of villagers. However, the elders rule is unrecoverable, so villagers use the democratic negotiation system with the characteristic of modern organization form, combining with open, fair and impartial modern cooperation concept, so the council has become the main form of rural self-organization. The council follows modern organizational structure and makes villagers choose the procedure of decision-making, decide director and director candidates, and determine the time and the way of participation of the worship activity of annual village temple by collective form. The most important thing is to advocate villagers remembering they all have a common source, and the present situation of Dongling village depends on the help and support from each other in the past. With the deepening of villagers' participation, the memories of a whole village helping one household wake up again and the spontaneous, voluntary public orientation make villagers be willing to seek the relationship which has been neglected in the civil affairs---whether blood or geographical relationship, villagers prefer to believe that this is the God's blessing. Therefore, not only the worship of ancestors, weddings and funerals, but also giving birth to a child and celebrating birthday, school or work etc. that all begin relying on the council to handle. Whether it is to go out to study, work as a worker or official or do farm ring or business at home, Dongling village returns to villagers' heart again and becomes an irreplaceable soul belong.

In the survey we learn about that villagers have a deep sense of identity to the council, they believe that the existing of council exerts great promoting effects on the development of village, which is reflected in culture, economy, stability and other aspects of the village. First, in the aspect of rural traditional culture, the existing of council plays an important role as a connecting link between the preceding and the following, which not only inherits rural traditional culture, but also promotes the development of rural new culture. Second, in the aspect of rural economy, council as a villager's selforganization represents the appearance of village to outside world in some ways. It propagandizes the affiliated village by a variety of ways and shapes an image of external propaganda, and can carry out patronage and resource for a variety of economic activities of the village, which is a strengthener for the development of rural economy. Besides, in the aspect of security, the council not only assists village committee to manage and educate villagers in the corresponding functional scope, and propagandizes all kinds of rules and regulations in cultural activity, and conducts villagers to be good law-abiding citizens. It has produced a good objective force on the public level, effectively reducing the crime rate, and the presentation of this kind of function also promotes rural community to replace traditional and backward elders rule with council, making it become a stabilizer for villagers' social activity. Meanwhile, the council, as an organization representative of village cultural reconstruction and new rural cultural construction, reaffirms the collective belief of village. Under this united belief, the council resists and resolves the individual contradictions in the development of modern society, and the trend of villages' relationship also towards the direction of compromise and cooperation, which sweeps away the obstacles for the public utilities construction of rural community and fine tradition of helping the weak, such as financing college students and poor families, effectively promoting the construction of harmonious countryside. 


\section{CONCLUSION}

Generally speaking, there are some achievements and high attention in the study of rural self-organization in China. As our country put forward the "Three Rural Issues", more and more scholars begin to pay attention to the problems of rural areas, and many of them have a high reputation, such as Yu Jianrong, Yu Keping, Qiao Xinsheng and others. They positively devote themselves into rural area and do some discussion and research about the existing problem of rural area and achieve some fruitful results. However, many scholars just put emphasis on rural self-organization or only study the problem of rural cultural reconstruction, and they pay less attention to the combination of self-organization and cultural reconstruction. At present, after my preliminary investigation I find that the rural self-organization, especially with the connotation of traditional clan revival nature, has great impetus to rural cultural reconstruction, which is an organization way to effectively connect the broken traditional culture. Hence, it is vital to make clear the relationship between self-organization and cultural reconstruction. Firstly, we make out the distinction of rural autonomous organization and self-organization and discuss the relationship between self-organization and rural cultural reconstruction. Furthermore, we point out that the authority of self-organization mostly comes from the rural specific group relations, and provides specific protection function to rural traditional culture and promotes modern traditional reconstruction, which makes it possible to reconstruct rural culture. But cultural reconstruction narrows the differences of individual with group and groups in rural community, and creates new energy and strength for group's identification and cohesion. Secondly, through analyzing and sorting the relationship of self-organization and cultural reconstruction, we can dig out the influence of modern folk religion on rural politics and economy. It also reveals that cultural reconstruction strengthens the civilizing function of the folk belief to groups, and enhances group's self-discipline and regulation behavior, and benefits to maintain good social and economic order in rural areas. In a word, in the pursuit of economic development and personal independence of our modern society, rural self-organization has become an important part of rural cultural reconstruction and community public cultural life. It provides a great organization guarantee and intellectual support for maintaining the stability and harmony of rural areas and promoting the construction of new socialist rural construction.

\section{REFERENCES}

[1] Fu Qiong, Cao Guoqing, Sun Kejing. Network Construction of Rural Informal Organization and New Power and Culture[J]. Jiangxi Social Sciences, 2013(5).

[2] Qiu Guiming. On the Self-organization of Farmers - Controversial New Theory in the Construction of a Rural Practice[J]. Journal of Jiangxi University of Finance and Economics, 2008(2).

[3] Li Yongcai, Yuan Yonghong. Loss and Revival of Atomized Selforganizing Abilities of Peasants[J]. Journal of Chongqing Institute of Technology, 2006(1).

[4] Wu Jie. Research on the Construction of Farmers' Self-Organization Ability in the Construction of New Countryside in Poverty Areas[J]. Adult and Society, 2013(8).
[5] H•Haken [Germany]. Information and Self-Organization[M]. This Book Translation Group, Translate. Chengdu: Si Chuan Education Press, 2010: 16.

[6] Xing Jun. On Self-Organization and Enterprise Management Efficiency[J]. Science \& Technology International, 2002(6).

[7] Zheng Hangsheng. Discussion on the Modern Growth and the Invented Tradition [J]. Tianjing Social Science, 2008(3).

[8] Zhou Lihong. Research on the Self-Organization of Ethnic Minority Rural Communities-A Case Study on Yunnan Red Village[D]. Kunming: Master's Thesis in Sociology, Yunnan University, 2010.

[9] Cai Weihong, Zhong Xiaolin. The Construction of Harmonious Countryside from the Perspective of Rural Non-Governmental Organizations[J]. Agricultural Archaeology, 2007(6).

[10] Tian Jinna. A Study of the Rural Community Development Issue from the Perspective of Self-organization-Based on the Analysis of Three Rural Social Work Projects[D]. Kunming: Master's Thesis in Sociology, Yunnan University, 2011

[11] Tong Yuquan, Deng Guangyu. Effects of Non-governmental Organizations on Rural Intangible Cultural Heritage Conservation[J]. Journal of Guizhou University(Social Science), 2012(6).

[12] Zhang Xiaojun, Qi Haili. A Probe into Role of Rural Non-Government Organization in the Construction of New Countryside[J]. Xue Hui, 2008(2).

[13] Yu Jianrong. Why Should I Advocate Reconstructing the Peasant Association?[J]. Anhui Policy Making Consultation, 2003(4).

[14] Ruan Yunxing, Zhang Jing. What Is the Possibility of Endogenous Organization Resources of Villagers' Autonomy? -A Political Anthropology Study on Zhejiang Liu Laohui case[J]. Sociological Studies, 2009(3).

[15] Yang Ping. A Survey of the Patriarchal Clan System in Rural Areas of Zhanjiang[J]. Strategy and Management, 1994(2).

[16] Qiao Xinsheng. Three Discussions on Rural Issues of China[J]. China Township Enterprises, 2004(1).

[17] Wang Shouen. Folk Beliefs and Traditional Rural Society in the Perspective of Social History[J]. Historiography Quarterly, 2010(1).

[18] Jian Xufeng, Cao Tiantian. From "Delivered Culture" to "Self Managing Culture" - The Construction of New Rural Culture from the Perspective of Communication[J]. Journal of China University of Geosciences (Social Sciences Edition), 2012(4).

[19] Liu Wei. A Cause Analysis of Low Degree of Farmers' SelfOrganization[J]. Journal of the Party School of CPC Ningbo, 2004(5).

[20] Yu Jianrong. The Development and Growth of Farmers' Rights Protection Organizations in Contemporary China -- An Empirical Study Based on Hengyang Peasant Association[J]. China Rural Survey, 2005(2).

[21] Zhang Dinggui. Embodied Self-Organization Mechanism of Cultural Tradition and Development of Rural Communtity - A Case Study on Jiuxi Village[J]. Journal of Anshun Teachers College, 2005(1).

[22] Cao Jinqing. At the edge of the Yellow River in China.[M]. Shanghai: Shanghai Literature and Art Publishing House, 2000:764 767.

[23] Wang Yuling. On the Strategic Choice and the Solutions of the Rural Cultural Reconstruction[D]. Fuzhou: Master's Thesis in the Department of Agricultural Economics and Management, Fujian Agriculture and Forestry University, 2007. 